\title{
Trusting internal medicine in hard times
}

\author{
Gino Roberto Corazza • Marco Vincenzo Lenti • \\ Antonio Di Sabatino
}

Received: 31 December 2013/ Accepted: 7 January 2014/Published online: 21 January 2014

(C) SIMI 2014

The health system must adapt to the changing burden of disease. Changes in environmental and social conditions, new individual behaviors, emerging causative factors, and even innovative diagnostic technologies and therapeutic capacity contribute to determining these continuous transformations [1].

Internal medicine has been traditionally considered as the epitome of medical education, and whether it is still able to deal with the changing task of medicine is under debate. Actually, its true meaning is not always understood, even among medical educators, students, health-care practitioners, and policy makers. Its original definition pointed to diseases of the internal organs, but after William Osler, internal was no longer considered to refer to the body, but to the 'inside' of the clinical problem [2, 3]. Thus, the definitive connotations of this specialty were clarified: generally oriented, covering a wider field than other specialties characterized by narrow-minded routine or devotion to a particular technique; scientifically driven, applying laboratory sciences to clinical work; hospital based, applying to a clinical domain different from family practice, and humanistically focused, stressing the importance of the doctor-patient relationship [3].

This model of consultant physician, albeit affected by recurrent crises, lasted right through the twentieth century,

G. R. Corazza - M. V. Lenti - A. Di Sabatino

First Department of Internal Medicine, St. Matteo Hospital, University of Pavia, Pavia, Italy

\author{
A. Di Sabatino \\ e-mail: a.disabatino@smatteo.pv.it
}

G. R. Corazza $(\square)$

Clinica Medica I, Fondazione IRCCS Policlinico San Matteo, Università di Pavia, Piazzale Golgi 19, 27100 Pavia, Italy

e-mail: gr.corazza@smatteo.pv.it and has been handed down to our generation of physicians. The most important and longest of these crises, which challenged the existence of internal medicine as a specialty, began around the 1950s, and reached a peak in the early 1990s [4]. The huge progress made by biomedical science meant, on the one hand, that it became impossible for anyone to master internal medicine in its entirety, and, on the other, the need to translate this progress into advanced clinical services provided by highly specialized physicians. This growing fragmentation of medical knowledge and practice led to the fact that the optimal use of economic and technological resources does not correspond to the maximal use of them being overlooked.

How did internal medicine react to this widespread and costly reductionism in clinical reasoning? It apparently did not react, but a number of trends became selected and accentuated almost automatically: the holistic approach, which focuses on the patient as an individual rather than on organs or diseases, and the methodological approach, which consists in rearranging the clinical picture in a more easily and interpretable way. In internal medicine, the very extent of the doctrine made it necessary to develop strategies aimed at improving clinical reasoning [5].

The question arises as to whether internal medicine, with these characteristics that at a first glance are not so innovative, can in fact adapt to the challenge of these changes. In the past few years, this difficult task has been further complicated by a global financial crisis whose duration and consequences are difficult to foresee [6]. This crisis is the most serious economic downturn witnessed since the 1930s, which unlike previous ones, started in the most developed countries, severely affecting health spending, health services, health-seeking behavior and health outcomes [7]. Nevertheless, while it is true that the 
global recession is likely to damage our wealth as well as our health, it may represent an opportunity to build a new health-care system that is less duplicative and glamorous, but more equitable and efficient.

In view of the unavoidable recourse to cost-effective strategies, internal medicine represents an appropriate model for intervention because of the priority attributed to clinical reasoning over technical ability and technological instruments, and of its proved flexibility both in the various health-care settings (outpatient clinics, hospital wards, intensive care units) as well as in relation to the transformations in clinical medicine, e.g., the shift from infectious diseases to chronic degenerative diseases as the main cause of morbidity and mortality, and the consequent increase in multimorbidity and polytherapy in geriatric [8] and pre-geriatric age [9]. Noteworthy, the Royal College of Physicians has recently produced a document dedicated to the Future Hospital, based on a more general vision of care and, therefore, more suitable for patients with multimorbidity, where internal medicine is responsible for all medical services within the hospital [10].

\section{Conflict of interest None}

\section{References}

1. Jones DS, Podolsky SH, Greene JA (2012) The burden of disease and the changing task of medicine. N Engl J Med 366:2333-2338

2. Bean WB (1982) Occasional notes. Origin of the term "internal medicine". N Engl J Med 306:182-183

3. Stevens R (1986) Issues for American internal medicine through the last century. Ann Intern Med 105:592-602

4. Cassel CK, Reuben DB (2011) Specialization, subspecialization, and subsubspecialization in internal medicine. $\mathrm{N}$ Engl $\mathrm{J}$ Med 364:1169-1173

5. Bowen JL (2006) Educational strategies to promote clinical diagnostic reasoning. N Engl J Med 355:2217-2225

6. de Belvis AG, Ferrè F, Specchia ML et al (2012) The financial crisis in Italy: implications for the healthcare sector. Health Policy 106:10-16

7. Marmot MG, Bell R (2009) How will the financial crisis affect health? BMJ 338:b1314

8. Nobili A, Garattini S, Mannucci PM (2011) Multiple diseases and polipharmacy in the elderly: challenges for the internist of the third millennium. J Comorbidity 1:1-17

9. Barnett K, Mercer SW, Norbury M, Watt G, Wyke S, Guthrie B (2012) Epidemiology of multimorbidity and implications for health care, research, and medical education: a cross-sectional study. Lancet 380:37-43

10. Future Hospital Commission (2013) Future hospital: caring for medical patients. A report from the Future Hospital Commission to the Royal College of Physicians. Royal College of Physicians, London 